\title{
Optical properties of copper-oxygen planes in superconducting oxides and related materials
}

\author{
M. K. Kelly, P. Barboux, ${ }^{*}$ J.-M. Tarascon, and D. E. Aspnes \\ Bellcore, Red Bank, New Jersey 07701-7040
}

(Received 17 April 1989)

\begin{abstract}
The optical spectra of $\mathrm{YBa}_{2} \mathrm{Cu}_{3} \mathrm{O}_{7-x}$ and other $\mathrm{Cu}$-O-based superconductors have several common features in the visible and near uv. Chemical changes that affect the conductivity of these materials also have a strong effect on some of these features. By comparing the spectra of many materials containing similar Cu-O structures, we have determined that some of the optical features are associated with specific local structures within the unit cell. Of particular interest is a sharp feature at $1.7 \mathrm{eV}$ that appears for nonmetallic compositions of many of the materials and is removed by the introduction of carriers. Similar features in materials not yet showing superconductivity encourage further investigation of them.
\end{abstract}

\section{INTRODUCTION}

While the copper-oxygen-based high-temperature superconductors exist in several families differing in structure and constituent elements, they all share perovskitetype $\mathrm{Cu}-\mathrm{O}$ planes as substructures. It is therefore especially important to understand the electronic properties of these planes. It is also valuable to know the extent to which these planes may be considered separately, since the unit cells of these materials consist of complicated combinations of ionic and covalent bonding and transition-metal multivalency. Problems that need to be addressed include the limitations of one-electron band theory, correlation effects and degree of hybridization of $\mathrm{Cu} 3 d$ orbitals, and localization effects due to substructural isolation and tight-binding character. The importance of lattice distortions and vacancies as well as spin-spin interactions also remains uncertain.

The chemical diversity of these materials provides one of the most helpful approaches to dealing with their complexity. By studying the effects of structural and compositional differences among the superconductors and related materials, much has already been learned about the factors that contribute to superconductivity and other properties. Such studies indicated that carriers introduced into nonconducting compositions by increasing oxygen composition (as in $\mathrm{YBa}_{2} \mathrm{Cu}_{3} \mathrm{O}_{7-x}$ ) or by substituting cations with different valences (as in $\mathrm{La}_{2-x} \mathrm{Sr}_{x} \mathrm{CuO}_{4-\delta}$ ) are responsible for the metallic and superconducting character. $^{1,2}$ Comparisons that showed that superconductivity is strongly affected by substituting other transition metals for $\mathrm{Cu}$ emphasized the delicate importance of the copper-oxygen planes. ${ }^{3}$

In our optical studies, we use the chemical diversity to understand the electronic structure responsible for visible and near-ultraviolet optical spectra. As this energy range gives information on chemical bonding, these measurements help us to understand the relationship between chemical structure and the electronic properties of the materials. Much of our effort has been directed towards understanding the strong optical features that are associ- ated with oxygen deficiency in $\mathrm{YBa}_{2} \mathrm{Cu}_{3} \mathrm{O}_{7-x}$, as reported in an earlier paper. ${ }^{4}$ By finding other compounds that show similar features, we have identified specific chemical substructures that are responsible for these features. This in turn has indicated the importance of the oxygen coordination of copper to the optical spectra and to transport properties.

\section{EXPERIMENT}

Since the selection of samples is closely tied to the study of specific optical features, we discuss individual materials with our results. Specific references to synthesis details are given there. In general, samples were fabricated by a solid-state reaction of appropriate ratios of powdered materials under controlled gas environments to obtain desired stoichiometries and phases. ${ }^{5}$ This method yielded samples of ceramic quality and allowed a wide variety of materials to be prepared and studied. Samples were characterized by x-ray powder diffraction. Oxygen stoichiometries were determined by iodometric titration, and superconducting transition temperatures $\left(T_{c}\right)$ were measured by ac susceptibility using a SQUID magnetometer.

In optical studies of these materials, it is necessary to deal with the complications resulting from their randomly oriented anisotropic multigrained nature. Flat, polished surfaces were prepared using a slurry of $0.05-\mu \mathrm{m}$ alumina suspended in methanol on a glass plate. Residual polishing damage was reduced with a finish lap using the same slurry on a single sheet of lens paper. Although these surfaces were still rough due to their multigrained nature, the scattering from grain boundaries and voids is not critical for measurement by ellipsometry, which does not rely on absolute intensities. Our confidence in this surface preparation method follows from reproducibility of results, favorable comparisons among different laboratories, and measurements on thin films and single crystals that did not require polishing.

A spectroscopic ellipsometer, described elsewhere, ${ }^{6}$ was used to measure the complex reflectance ratios be- 
tween reflectances parallel and perpendicular to the plane of incidence over an energy range of 1.5 to approximately $5.8 \mathrm{eV}$. From these measurements, the complex pseudodielectric function, $\epsilon=\epsilon_{1}+i \epsilon_{2}$, was calculated in the two-phase model, which assumes an isotropic sample and air ambient. This is an approximation for these materials, but studies on oriented samples have shown that the anisotropy in this energy range is mild. ${ }^{7}$ The anisotropic, multigrain nature of the materials causes a spread of polarization information, the primary result of which is some uncertainty in the absolute value of $\epsilon_{2}$. However, the structure of the spectra is not obscured and comparisons with oriented-film and single-crystal data of some of the materials indicate that this uncertainty is small.

\section{III. $\mathrm{YBa}_{2} \mathrm{Cu}_{3} \mathrm{O}_{7-x}$}

The most intriguing aspect of the visible-nearultraviolet studies is the oxygen-composition dependence of the strong localized absorption features in $\mathrm{YBa}_{2} \mathrm{Cu}_{3} \mathrm{O}_{7-x}$. This is particularly interesting because of the strong effect that oxygen stoichiometry has on the transport properties in this material. ${ }^{1}$ The compound is stable for compositions between $x=0$ and 1 . When $x$ is near 0 , the material has its highest conductivity and critical temperature for superconductivity. Both conductivity and $T_{c}$ decrease with oxygen content. For $x$ greater than $\sim 0.6$ the material shows temperature-dependent resistivity like a semiconductor and superconductivity does not occur.

Spectra for high- and low-oxygen stoichiometries are shown in Figs. 1(a) and 1(b). The low-oxygen spectrum shows strong features at 1.7 and $4.1 \mathrm{eV}$. These features have been observed by ellipsometry, ${ }^{4,8,9}$ absorptance in thin films, ${ }^{10}$ reflectance, ${ }^{11,12}$ and electron energy loss. ${ }^{13}$ Experiments involving substitution of rare-earth elements on the $\mathrm{Y}$ sites and $\mathrm{Sr}$ on the $\mathrm{Ba}$ sites showed that the low-oxygen features are largely independent of these elements. ${ }^{4}$ As an example, the spectrum for low-oxygen $\mathrm{YSr}_{2} \mathrm{Cu}_{3} \mathrm{O}_{7-x}$ is shown in Fig. 1(c). Although this material is difficult to make, we succeeded in obtaining a single phase sample (as determined by $x$-ray diffraction). This material was made with a stoichiometric mix of $\mathrm{SrCO}_{3}, \mathrm{Y}_{2} \mathrm{O}_{3}$, and $\mathrm{CuO}$, that was repeatedly ground and annealed at $920^{\circ} \mathrm{C}$. The phase is probably stabilized with small amounts of impurities incorporated during the several anneals as suggested in previous studies. ${ }^{14}$ The sample showed a broad superconducting transition beginning at $80 \mathrm{~K}$, and an optical spectrum similar to that of superconducting $\mathrm{YBa}_{2} \mathrm{Cu}_{3} \mathrm{O}_{7-x}$. Removal of oxygen by annealing in argon resulted in the two strong optical features shown in the figure.

Through these studies we concluded that the $4.1 \mathrm{eV}$ feature originates in a transition on linear $\mathrm{O}-\mathrm{Cu}^{+}-\mathrm{O}$ complexes that are localized as a result of oxygen vacancies. This assignment was encouraged by spectra of $\mathrm{K}_{2} \mathrm{CuCl}_{3}$ which also showed sharp features in this energy range. ${ }^{15}$ This compound also has isolated $\mathrm{Cu}^{+}$complexes. We have since obtained stronger confirmation of this assignment from $\mathrm{YCuO}_{2}$. This compound has the delafossite structure, with $\mathrm{O}-\mathrm{Cu}^{+}-\mathrm{O}$ linear complexes arranged in

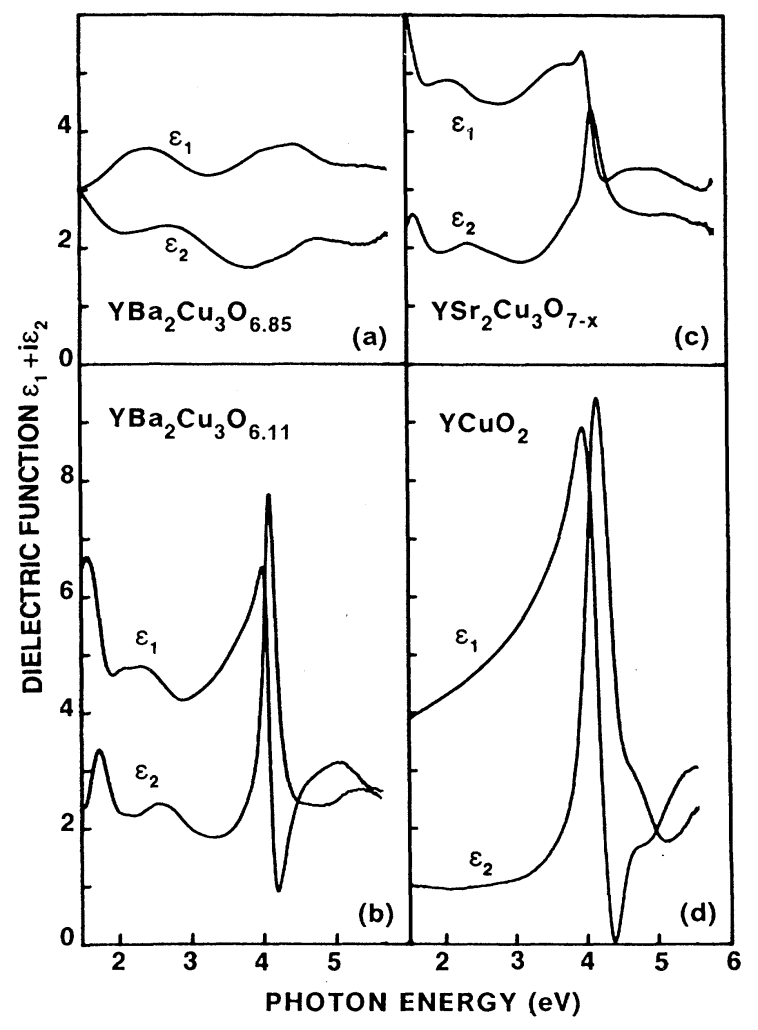

FIG. 1. Measured dielectric function $\epsilon_{1}+i \epsilon_{2}$ for materials chosen to emphasize the 1.7- and 4.1-eV absorption features: (a) $\mathrm{YBa}_{2} \mathrm{Cu}_{3} \mathrm{O}_{6.85}, T_{c}=90 \mathrm{~K}$; (b) $\mathrm{YBa}_{2} \mathrm{Cu}_{3} \mathrm{O}_{6.11}, T_{c}=0 \mathrm{~K}$; (c) lowoxygen $\mathrm{YSr}_{2} \mathrm{Cu}_{3} \mathrm{O}_{7-x}, T_{c}=0 \mathrm{~K}$; (d) $\mathrm{YCuO}_{2}$. All measurements were made at room temperature.

planes between positive ionic layers as in $\mathrm{YBa}_{2} \mathrm{Cu}_{3} \mathrm{O}_{6} \cdot{ }^{16}$ The spectrum for this compound is shown in Fig. 1(d) and exhibits a feature at $4.2 \mathrm{eV}$ that is strikingly similar to the 4.1-eV feature of $\mathrm{YBa}_{2} \mathrm{Cu}_{3} \mathrm{O}_{6}$. The 4.2-eV feature in $\mathrm{YCuO}_{2}$ can be modeled with a Lorentzian line shape of width $\Gamma=0.43$ and strength $E_{p}^{2}=4 \pi n e^{2} / m^{*}=15.5 \mathrm{eV}^{2}$. This is three times as strong as the peak for $\mathrm{YBa}_{2} \mathrm{Cu}_{3} \mathrm{O}_{6.11}{ }^{4}$, which corresponds well to the site density ratio for the two materials (2.87) when we assume that only one $\mathrm{Cu}$ atom per unit cell is active in $\mathrm{YBa}_{2} \mathrm{Cu}_{3} \mathrm{O}_{6}$. Thus, we are confident that the optical feature can be associated with the localized $\mathrm{O}-\mathrm{Cu}^{+}-\mathrm{O}$ complex.

This assignment encourages us to consider the substructures of the unit cell. In Fig. 2 we show the crystal structure of $\mathrm{YBa}_{2} \mathrm{Cu}_{3} \mathrm{O}_{7-x}$, as well as those of two other superconducting materials, $\mathrm{La}_{2-x} \mathrm{Sr}_{x} \mathrm{CuO}_{4-\delta}$ and $\mathrm{Bi}_{2} \mathrm{Sr}_{2} \mathrm{Ca}_{1} \mathrm{Cu}_{2} \mathrm{O}_{8} \cdot{ }^{17}$ The figure emphasizes the oxygen coordination at the copper sites. $\mathrm{YBa}_{2} \mathrm{Cu}_{3} \mathrm{O}_{7-x}$ has two distinct copper sites, commonly labeled $\mathrm{Cu}(1)$ and $\mathrm{Cu}(2)$. The $\mathrm{Cu}(2)$ sites have square-pyramidal coordination with five oxygen atoms, and are arranged in planes by sharing corners of the pyramid bases. The unit cell has two such planes with the apexes in opposing directions. These planes are the common element of the $p$-type carrier superconductor families with the exception of 

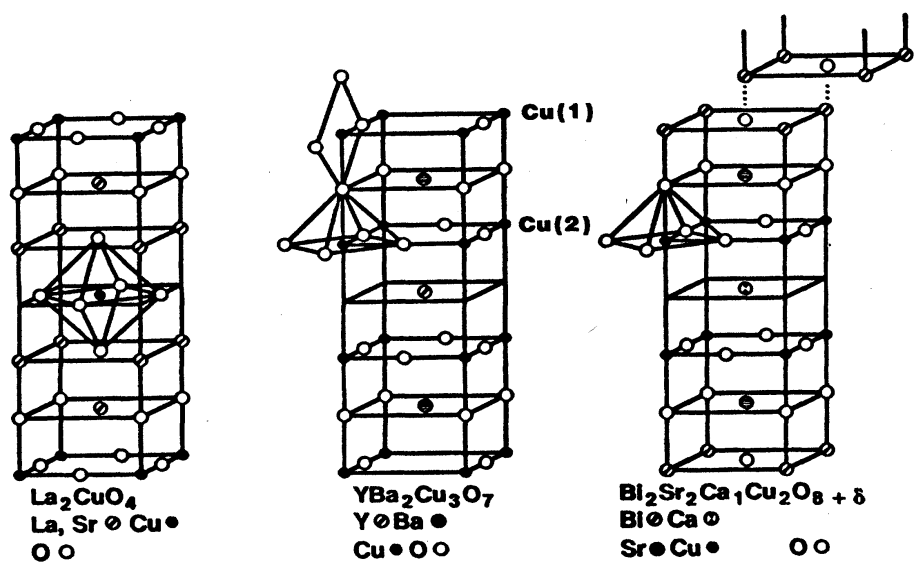

FIG. 2. Crystallographic structure for three $\mathrm{Cu}-\mathrm{O}$ based superconductors. The oxygen coordination of the $\mathrm{Cu}$ sites is emphasized. After Ref. 17.

$\mathrm{La}_{2-x} \mathrm{Sr}_{x} \mathrm{CuO}_{4-\delta}$, which has $\mathrm{Cu}-\mathrm{O}$ planes with sixfold octahedral oxygen coordination at the $\mathrm{Cu}$ sites. In all of these cases, the bond lengths to the four oxygen atoms in the plane are shorter than those to the one or two apex oxygen atoms.

The $\mathrm{Cu}(1)$ sites are also arranged in a plane with similar spacing, but the occupation of the oxygen sites in the plane is not complete. At $x=0$, only half of the sites are occupied, and they are ordered in chains of alternating $\mathrm{Cu}$ and $\mathrm{O}$, resulting in orthorhombic crystal symmetry with anisotropy between the $a$ and $b$ directions in the plane as well as the $c$ direction perpendicular to the plane. Thus at this oxygen stoichiometry, the $\mathrm{Cu}(1)$ have a fourfold oxygen coordination with two oxygen atoms in the plane and two out of the plane. These out-of-plane oxygens are also the apexes of the $\mathrm{Cu}(2)$ sites. For higher values of $x$, oxygen is removed from the $\mathrm{Cu}(1)$ plane. Thus the $\mathrm{Cu}(1)$ plane has mixed oxygen coordination for intermediate $x$ values. At $x \gtrsim 0.5$ the ordering into chains, and consequent $a-b$ anisotropy, is lost. Finally, at $x=1$, there is no oxygen in the $\mathrm{Cu}(1)$ plane and the $\mathrm{Cu}$ sites are twofold coordinated to the apexes of the $\mathrm{Cu}(2)$ planes. At the same time, the bond length from these oxygen atoms to the $\mathrm{Cu}(1)$ atoms shortens from $1.83 \AA$ to a very low $1.80 \AA .{ }^{18}$

In order to consider the relation between the optical features and the oxidation state of $\mathrm{Cu}$ atoms, we also examined the two basic oxides, $\mathrm{Cu}_{2} \mathrm{O}$ and $\mathrm{CuO}$, which have copper valences of $1+$ and $2+$, respectively $(\mathrm{Cu} 3 d$ occupations of $d^{10}$ and $d^{9}$, respectively). The spectra for sintered and polished samples of these oxides are shown in Fig. 3. Neither shows the sharp features of $\mathrm{YBa}_{2} \mathrm{Cu}_{3} \mathrm{O}_{6}$, indicating that these features are not simply associated with a particular oxidation state of $\mathrm{Cu}$. Thus, although the stoichiometry dependence of the peaks suggests a link with $\mathrm{Cu}^{+}$, the difference between the $\mathrm{Cu}_{2} \mathrm{O}$ and $\mathrm{YBa}_{2} \mathrm{Cu}_{3} \mathrm{O}_{6}$ results indicates that the nature of the bonding plays a dominant role in these transitions.

As mentioned above, both $\mathrm{YCuO}_{2}$ and $\mathrm{K}_{2} \mathrm{CuCl}_{3}$ have spectra with features similar to the $4.1 \mathrm{ev}$ absorption in
$\mathrm{YBa}_{2} \mathrm{Cu}_{3} \mathrm{O}_{6}$. Both of these are easily identified as $\mathrm{Cu}^{+}$ compounds according to standard oxidation number assignment rules. The oxidation state of $\mathrm{Cu}$ in $\mathrm{YBa}_{2} \mathrm{Cu}_{3} \mathrm{O}_{7-x}$ is less simple. At $x=1$, the rules give an average oxidation number of +1.67 . The linear coordination of the $\mathrm{Cu}(1)$ atoms is a common geometry for the

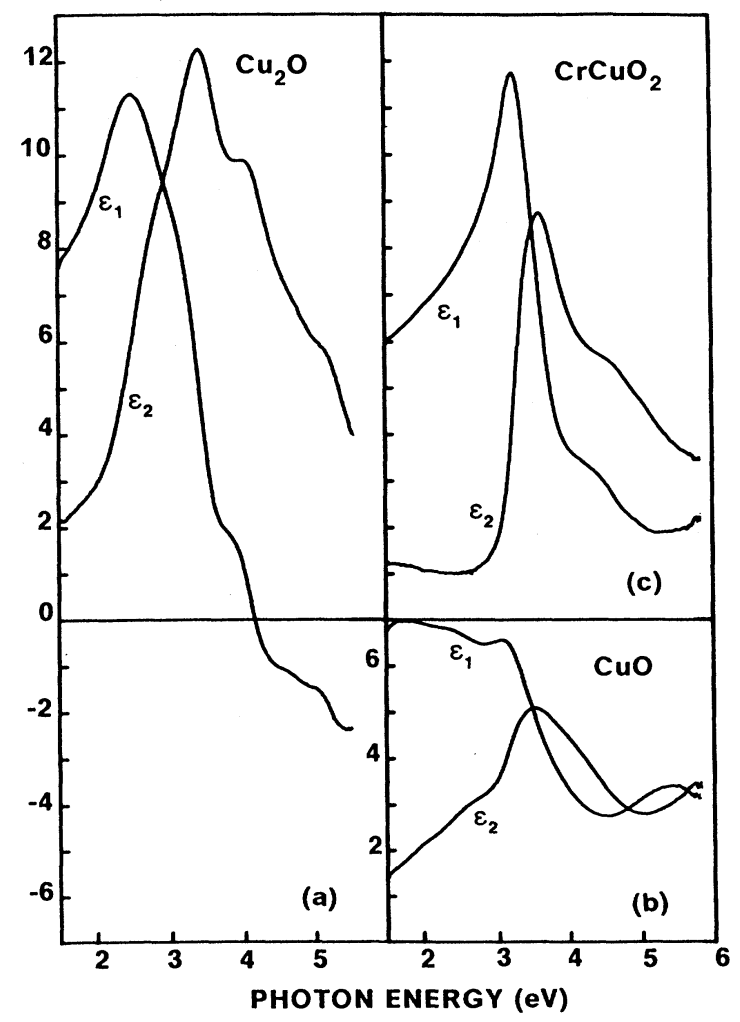

FIG. 3. Measured dielectric function for simple oxides of $\mathrm{Cu}$, (a) $\mathrm{Cu}_{2} \mathrm{O}$ with $\mathrm{Cu}^{+}$; (b) $\mathrm{CuO}$ with $\mathrm{Cu}^{2+}$; (c) $\mathrm{CrCuO}_{2}$ with $\mathrm{Cu}^{+}$ and the same structure as $\mathrm{YCuO}_{2}$. 
$\mathrm{Cu}^{+}$state. Therefore, to the extent that oxidation number is meaningful for these covalently bonded materials, a reasonable assignment is $1+$ for the linearly coordinated $\mathrm{Cu}(1)$ sites and $2+$ for the fivefold coordinated $\mathrm{Cu}(2)$ sites. As $x$ decreases, some of the $\mathrm{Cu}(1)$ sites become threefold or fourfold coordinated and the average oxidation number of $\mathrm{Cu}$ increases to +2 at $x=0.5$. At $x=0$, the average oxidation number reaches 2.33 , suggesting that some of the $\mathrm{Cu}$ atoms are in a $3+$ state. However, electron spectroscopy has not provided convincing evidence of a $\mathrm{Cu} d^{8}$ ground state but indicates instead that the surplus positive charge has greater presence at the oxygen sites and provides the delocalized holes that support conduction. ${ }^{19,20}$

Considering the similarity between the spectra of $\mathrm{YBa}_{2} \mathrm{Cu}_{3} \mathrm{O}_{6}$ and $\mathrm{YCuO}_{2}$, the $\mathrm{x}$-ray absorption evidence, ${ }^{21-23}$ the predictions of coordination chemistry, and the oxidation number, we therefore identify the linear $\mathrm{Cu}(1)$ site with the $\mathrm{Cu}^{+}$state. Since $\mathrm{Cu}^{+}$has a filled $3 d$ shell, this assignment has implications for the magnetic properties of the low-oxygen material. Our results for the intensity of the 4.1-eV feature as a function of oxygen content indicate that some linear complexes, and therefore some $\mathrm{Cu}^{+}$atoms, are present even for small concentrations of oxygen vacancies. Therefore, the energetic cost of pairing two oxygen vacancies about the same $\mathrm{Cu}(1)$ site must be small. Furthermore, the presence of $\mathrm{Cu}^{+}$in the $\mathrm{Cu}(1)$ plane means that even when the average oxidation number of $\mathrm{Cu}$ is less than +2 , there may still be holes in the $\mathrm{Cu}(2)$ planes that can support conduction. This indicates why these materials can show superconductivity for $x$ values slightly higher than 0.5 .

The presence of $\mathrm{Cu}^{+}$was also determined by $\mathrm{Cu} K$ edge $x$-ray absorption studies. ${ }^{21-23}$ In these studies, a sharp preedge absorption was attributed to transitions from the $\mathrm{Cu} 1 s$ orbital to antibonding states of $\pi$ character derived from the $\mathrm{Cu} 4 p$ orbitals. These studies further showed that the final-state orbitals were oriented parallel to the $a-b$ planes. $^{23}$ If the $4.1-\mathrm{eV}$ feature is also due to transition to this antibonding level, then this orientation is consistent with our observation of the feature from single-crystal surfaces parallel to the plane. Observations of the orientational dependence of the 4.1-eV transition indicate that it is highly directional, with low strength for light polarized perpendicular to the planes. ${ }^{24}$

Since $\mathrm{Cu}_{2} \mathrm{O}$ also shows the sharp $\mathrm{x}$-ray edge feature and has $\mathrm{Cu}$ atoms with twofold oxygen coordination, other details must be important to the existence of the sharp 4.1-eV feature. The $\mathrm{Cu}-\mathrm{O}$ bond lengths of $\mathrm{YBa}_{2} \mathrm{Cu}_{3} \mathrm{O}_{6}$, $\mathrm{YCuO}_{2}$, and $\mathrm{Cu}_{2} \mathrm{O}$ are $1.80,1.835$, and $1.85 \AA$, respective$1 y$, so a short bond length may favor the transition. The extended bonding and localization of the linear complex may also be important. The oxygen atoms are tetrahedrally bonded to four $\mathrm{Cu}$ atoms in $\mathrm{Cu}_{2} \mathrm{O}$, in contrast to the ionic environment of the linear $\mathrm{O}-\mathrm{Cu}-\mathrm{O}$ unit in $\mathrm{YBa}_{2} \mathrm{Cu}_{3} \mathrm{O}_{6}$ and $\mathrm{YCuO}_{2}$. A measure of the localization of the species is given by the distance between the $\mathrm{Cu}$ atoms, which are arranged in planes for all three materials. For $\mathrm{YBa}_{2} \mathrm{Cu}_{3} \mathrm{O}_{6}$, the copper atoms form a square lattice with a $\mathrm{Cu}-\mathrm{Cu}$ spacing of $3.856 \AA$. In the other two compounds, the $\mathrm{Cu}$ atoms form a hexagonal lattice with
$\mathrm{Cu}-\mathrm{Cu}$ spacings of $3.524 \AA$ for $\mathrm{YCuO}_{2}$ and $3.02 \AA$ for $\mathrm{Cu}_{2} \mathrm{O}$. The compound $\mathrm{CrCuO}_{2}$ has the same structure as $\mathrm{YCuO}_{2}$ but with a $\mathrm{Cu}-\mathrm{Cu}$ spacing of $2.975 \AA$. ${ }^{25}$ The $\mathrm{Cr}-\mathrm{O}$ bonding is also likely to be more covalent than that between $\mathrm{Y}$ and $\mathrm{O}$. Consequently, it is not surprising that the $\mathrm{CrCuO}_{2}$ spectrum is more like that of $\mathrm{Cu}_{2} \mathrm{O}$ [Fig. 3(c)]. Thus it appears that the "backbonding" of the $\mathrm{O}$ atoms and the degree of isolation of the O-Cu-O complex are both critical for the $4.1-\mathrm{eV}$ feature. A wide atomic spacing allows the active orbitals, which may be those derived from the $\mathrm{Cu} 4 p$ states within the plane, to remain localized and well defined in energy, rather than dispersed into a band as with $\mathrm{Cu}_{2} \mathrm{O}$. The 4.1-eV feature also seems to be favored by a short $\mathrm{Cu}-\mathrm{O}$ bond length.

We originally proposed that the $4.1-\mathrm{eV}$ feature was due to either a charge-transfer transition, $d^{10}-d^{10} s \underline{L}$, or an intraatomic transition, $d^{10}-d^{9} s .{ }^{4}$ Considering the above information these remain reasonable assignments, with the recognition that the $\mathrm{Cu} 4 s$ orbitals are most likely hybridized with the $\mathrm{Cu} 4 p$ and the $\mathrm{O} 2 p$ orbitals. However, considering the temperature-dependent data ${ }^{9}$ and the importance of the oxygen bonding, we agree with Humlíček et $a l .{ }^{9}$ that the charge-transfer transition is the better assignment. Addition of oxygen to the $\mathrm{Cu}(1)$ plane, with the corresponding change in $\mathrm{Cu}(1)-\mathrm{O}(4)$ bond length, apparently reduces the oscillator strength for this transition. The extra ligands in the $\mathrm{Cu}(1)$ plane probably also cause the final-state orbitals to be more dispersed in energy, broadening the absorption, which may be responsible for the absorption shoulder near $4.5 \mathrm{eV}$ in the superconducting composition. Garriga et al. also note that transitions involving the $\mathrm{Ba}$ and $\mathrm{O}$ may contribute to the spectrum in this energy range. ${ }^{8}$

The identification of this strong, easily identifiable optical feature with oxygen deficiency provides a useful method of characterizing oxygen content on surfaces, thin films, or interfaces. We have recently demonstrated this approach in studying the effect of metallic overlayers on the surface chemistry of this material. ${ }^{26}$

We now consider the 1.7-eV feature, which shows interesting behavior that is different from that of the $4.1-\mathrm{eV}$ feature. The latter is obtained only by creating oxygen vacancies in the $\mathrm{Cu}(1)$ plane. The $1.7-\mathrm{eV}$ feature also appears when the metallic character in $\mathrm{YBa}_{2} \mathrm{Cu}_{3-y} \mathrm{Co}_{y} \mathrm{O}_{7-x}$ is removed by substituting $\mathrm{Co}$ for $\mathrm{Cu}$, which occurs for $y>0.3 .^{3}$ The spectrum of highoxygen $\mathrm{YBa}_{2} \mathrm{Cu}_{2.4} \mathrm{Co}_{0.6} \mathrm{O}_{7-x}$ is shown in Fig. 4(a). Note the presence of the $1.7-\mathrm{eV}$ feature but the absence of a feature at $4.1 \mathrm{eV}$. Therefore the $1.7-\mathrm{eV}$ peak is more generally coupled to the suppression of metallic conductivity, rather than simply to a particular chemical change such as oxygen loss.

The 1.7-eV optical behavior is also more general with respect to structural families. A $1.7-\mathrm{eV}$ absorption appears in the superconductor $\mathrm{Bi}_{2} \mathrm{Sr}_{2} \mathrm{CaCu}_{2} \mathrm{O}_{8}$ when it is made nonconducting by substituting $\mathrm{Y}$ for $\mathrm{Ca}$, as seen in Fig. 4(b). ${ }^{17}$ Since all of these materials have the fivefold configured $\mathrm{Cu}$ sites, we measured samples of another material, $\mathrm{La}_{2} \mathrm{SrCu}_{2} \mathrm{O}_{6}$, that has not yet shown superconductivity, but also has planes like the $\mathrm{Cu}(2)$ planes. $^{27}$ As shown in Fig. 5, a feature at $1.7 \mathrm{eV}$ is again present and is 


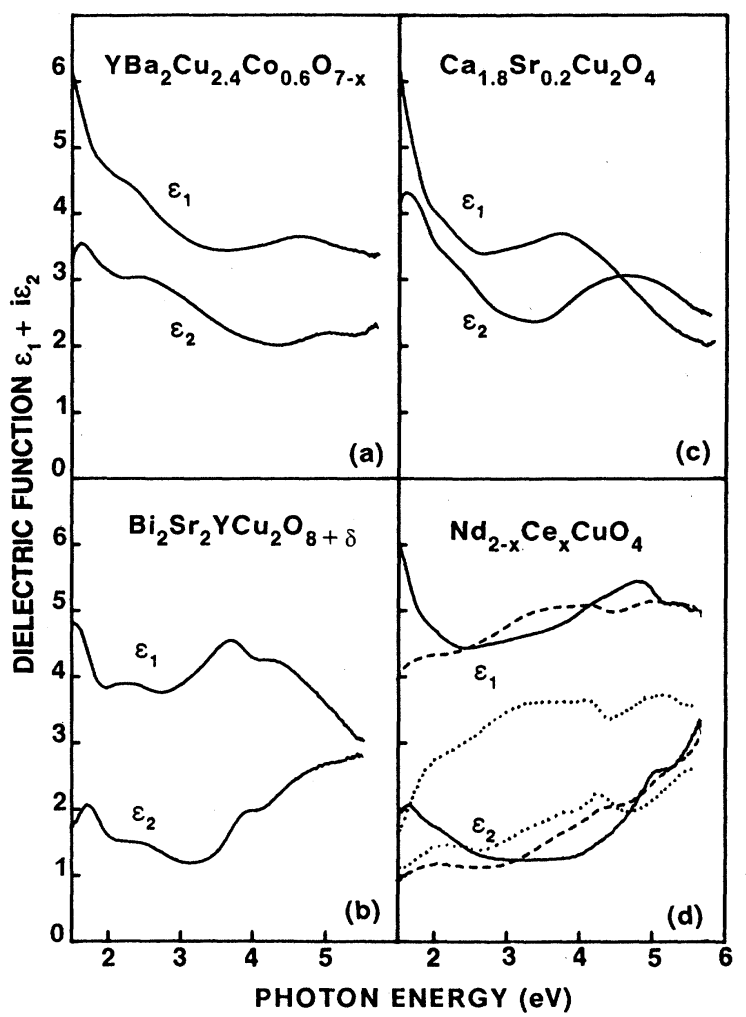

FIG. 4. Measured dielectric function for compounds exhibiting the $1.7-\mathrm{eV}$ feature, (a) and (b) with fivefold O-coordination of $\mathrm{Cu}$ sites, (c) and (d) with fourfold coordination. In (d), the solid curve is for $x=0$ (nonmetallic), the dashed curve is for $x=0.15$ (metallic and superconducting), and the dotted curve is for a single crystal with $T_{c}=15 \mathrm{~K}$.

stronger for material annealed in a low-oxygen atmosphere. These samples showed poor conductivity and low-temperature semiconducting behavior. The samples were also shown by $\mathrm{x}$-ray diffraction and the lack of a superconducting break transition to be free of $\mathrm{La}_{2-x} \mathrm{Sr}_{x} \mathrm{CuO}_{4-\delta}$, which could be an impurity in this material. While conductivity could be improved with oxygen-rich annealing, no superconductivity was observed.

We do not observe the 1.7-eV feature in $\mathrm{La}_{2-x} \mathrm{Sr}_{x} \mathrm{CuO}_{4-\delta}$, with sixfold coordination, which also has an insulator-metal transition as a function of $x$. The spectra for these samples were reported in Ref. 28. However, a more subtle feature at $2.1 \mathrm{eV}$ shows a doping dependence that is similar to that of the $1.7-\mathrm{eV}$ feature and may have related origin.

Although the differences between materials with sixfold and fivefold oxygen-coordinated $\mathrm{Cu}$ sites indicate that coordination may be critical to the $1.7-\mathrm{eV}$ feature, another difference between $\mathrm{La}_{2} \mathrm{CuO}_{4-\delta}$ and $\mathrm{YBa}_{2} \mathrm{Cu}_{3} \mathrm{O}_{6}$ is magnetic ordering. ${ }^{29,30} \mathrm{YBa}_{2} \mathrm{Cu}_{3} \mathrm{O}_{6}$ is antiferromagnetically ordered below $\sim 500 \mathrm{~K}$, while $\mathrm{La}_{2} \mathrm{CuO}_{4-\delta}$ is only ordered below room temperature. Temperaturedependent studies of the optical spectrum $\mathrm{YBa}_{2} \mathrm{Cu}_{3} \mathrm{O}_{6}$ showed a strong temperature dependence for the $1.7-\mathrm{eV}$

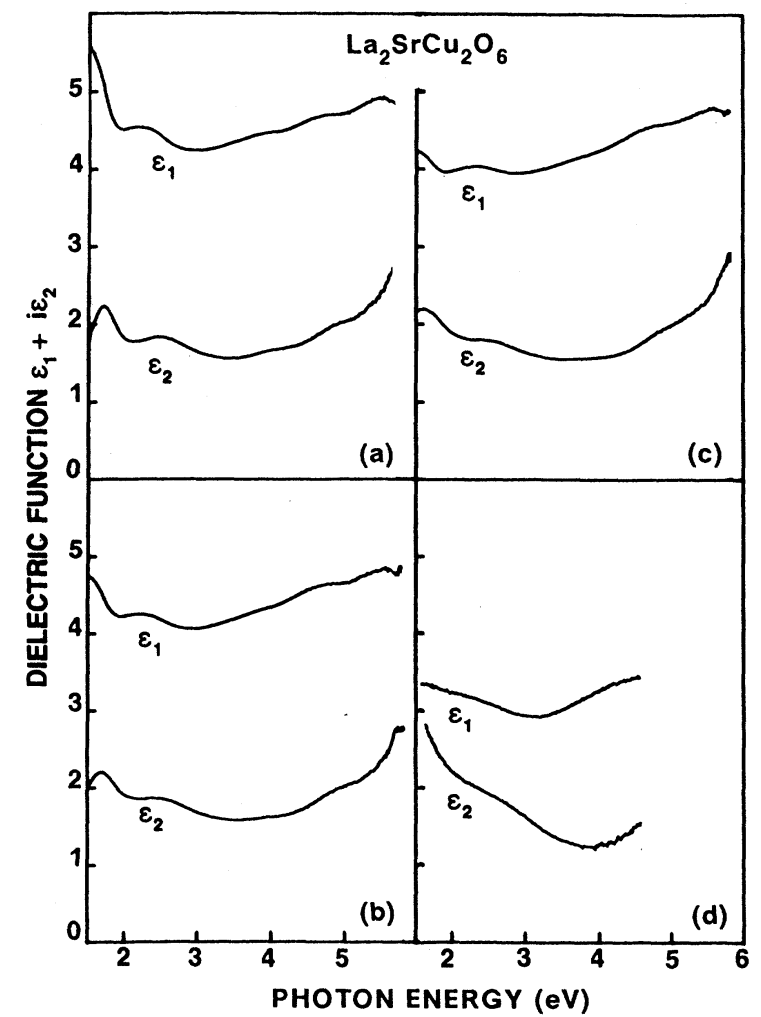

FIG. 5. Measured dielectric function for $\mathrm{La}_{2} \mathrm{SrCu}_{2} \mathrm{O}_{6}$ as a function of oxygen composition: (a) annealed in Ar; (b) annealed at $500^{\circ} \mathrm{C}$ in $\mathrm{O}_{2}$; (c) annealed at $800^{\circ} \mathrm{C}$ in $\mathrm{O}_{2}$; (d) annealed at $800^{\circ} \mathrm{C}$ under $50 \mathrm{~atm} . \mathrm{O}_{2}$.

feature, but no correlation with the Néel temperature. ${ }^{9}$ We made similar measurements that are in agreement with these results. Cooling $\mathrm{La}_{2} \mathrm{CuO}_{4-\delta}$ below its Néel temperature also produced no sharp change in the optical spectrum.

To further investigate the role of oxygen coordination, we synthesized and measured two more materials whose structure consists of perovskite-type $\mathrm{Cu}-\mathrm{O}$ planes, but without apex oxygen, resulting in fourfold square-planar coordination of the $\mathrm{Cu}$. These materials are $\mathrm{Ca}_{1.8} \mathrm{Sr}_{0.2} \mathrm{Cu}_{2} \mathrm{O}_{4},{ }^{31}$ and $\mathrm{Nd}_{2} \mathrm{CuO}_{4} \cdot{ }^{32}$ Neither are metallic or superconducting. The former has alternating planes of $\mathrm{Cu}-\mathrm{O}$ and $\mathrm{Ca}$, an extension of a structure in the $\mathrm{Bi}$ containing $\mathrm{Cu}-\mathrm{O}$ superconductors. $\mathrm{Nd}_{2} \mathrm{CuO}_{4}$ has a structure (labeled $T^{\prime}$ ) which is a variation of the $\mathrm{La}_{2} \mathrm{CuO}_{4}$ structure, with $\mathrm{Cu}-\mathrm{O}$ planes separated by $\mathrm{Nd}-\mathrm{O}-\mathrm{Nd}$ sandwichlike layers.

The spectra for these materials are shown in Figs. 4(c) and 4(d). Both show features slightly below $1.7 \mathrm{eV}$, with similar strengths and widths. Thus the planes of fourfold and fivefold $\mathrm{Cu}$ sites show similar electronic structure in this energy range that is indirectly related to conductivity. It is tempting to view these two materials, as well as $\mathrm{La}_{2} \mathrm{SrCu}_{2} \mathrm{O}_{6}$, as being similar to undoped superconducting materials, and to investigate the possibility of inducing superconductivity by chemical doping. In fact, a superconductor produced by doping the $T^{\prime}$ structure with 
Ce ( $n$ type rather than $p$ type) was recently reported..$^{33}$ As shown in Fig. $4(\mathrm{~d}), \mathrm{Nd}_{2} \mathrm{CuO}_{4}$ also loses the 1.7-eV feature when the material becomes conducting. Thus both $n$ - and $p$-type carriers can suppress this feature. Note also the increase in spectral weight near $4 \mathrm{eV}$ which suggests a change in $\mathrm{Cu}$-related transitions, probably due to the presence of $\mathrm{Cu}^{+}$. A spectrum from a single-crystal sample that was recently synthesized and showed superconductivity at $T_{c}=15 \mathrm{~K}$ (Ref. 34 ) is also shown. The lower value of $\epsilon_{1}$ for this (001) surface is consistent with higher conductivity parallel to the $\mathrm{Cu}-\mathrm{O}$ planes, as with the $p$-type materials.

Having established that the $1.7-\mathrm{eV}$ feature originates in $\mathrm{Cu}-\mathrm{O}$ planes with fourfold or fivefold oxygen coordination of the $\mathrm{Cu}$ sites, we wanted to see if this coordination of $\mathrm{Cu}$ was sufficient to produce the feature or if the extended plane structure was also important. We investigated this by considering samples that again have $\mathrm{Cu}$ in square-planar or square-pyramidal coordination with oxygen, but where the sites are no longer arranged in the perovskite-type structure, either by being more isolated from neighboring sites by bonds to other ions, or arranged in more complex three-dimensional structures. These include $\mathrm{BaCuO}_{2}$ (Ref. 32) and $\mathrm{Y}_{2} \mathrm{CuBaO}_{5},{ }^{35}$ which are common impurity phases, $\mathrm{La}_{4} \mathrm{BaCu}_{5} \mathrm{O}_{13}$, and $\mathrm{La}_{5} \mathrm{SrCu}_{6} \mathrm{O}_{15}{ }^{27}$ Their spectra, which are shown in Fig. 6

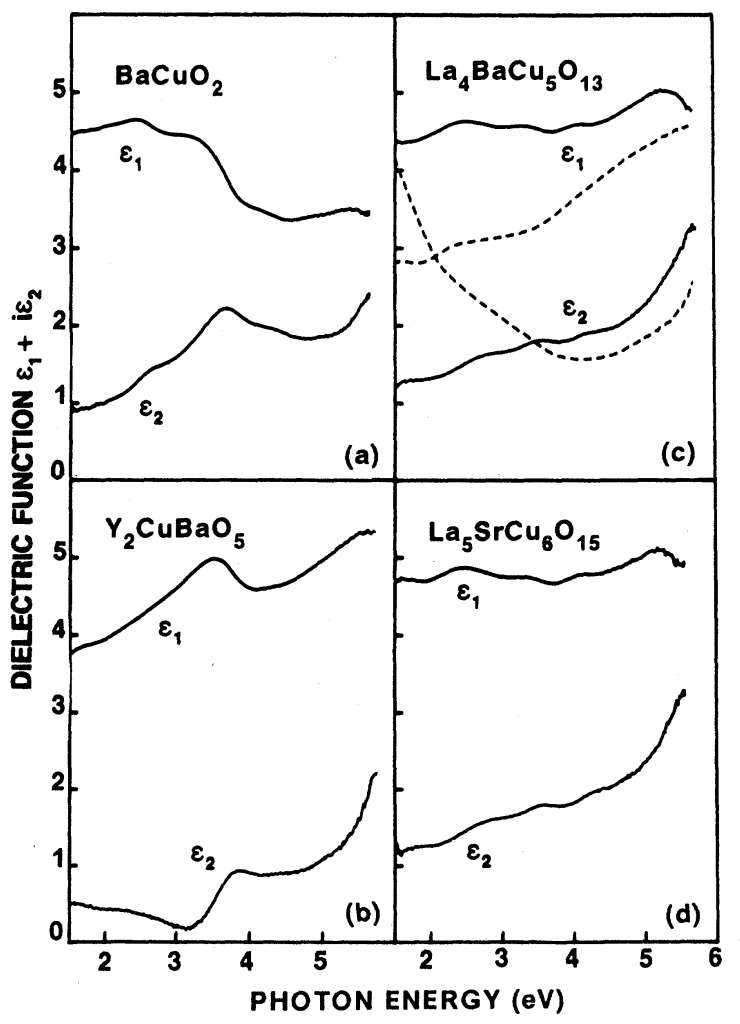

FIG. 6. Measured dielectric function for materials with fourfold and fivefold $\mathrm{O}$ coordination of $\mathrm{Cu}$ sites, and nonplanar extended configuration of sites. The dashed curve corresponds to oxygen-rich composition. do not have the $1.7-\mathrm{eV}$ feature. This confirms the importance of the extended two-dimensional $\mathrm{Cu}-\mathrm{O}$ structure.

The dependences of this optical feature on oxygen coordination and on the extended structure among the $\mathrm{Cu}-\mathrm{O}$ sites suggest again a charge-transfer-type origin. Considering the oxidation state of the $\mathrm{Cu}(2)$ atoms and the energy of the feature relative to the $d^{10} s \underline{L}$ excitation, a $d^{9}-d^{10} \underline{L}$ transition is the probable origin. This is consistent with conclusions based on temperature and pressure dependence. ${ }^{9,11}$ In particular, the feature grows weaker, broader, and slightly lower in energy with increasing temperature. This is opposite to the behavior that might be expected for an intraatomic $d$ - $d$ transition if thermal fluctuations contributed to reduced symmetry and increased oscillator strength for this dipole-forbidden transition. Another possibility to consider is an intervalent charge fluctuation, such as $d^{9}+d^{9}-d^{10}+d^{8}$. The importance of the extended structure among $\mathrm{Cu}$ sites supports this type of assignment. However, work by Zaanen et al. ${ }^{36}$ indicates that the energy for this transition for copper oxide should be much higher and that the material should show a ligand-metal charge-transfer gap instead. Spectroscopic studies on the superconducting materials also suggest that the $d$ - $d$ interaction energy involved in the $d^{8}$ state should be $5-10 \mathrm{eV} .{ }^{37}$ Thus, the transition appears to be due to a bound charge-transfer excitation, as proposed in Ref. 9, and determines a key energetic parameter in the material.

Our measurements on single crystals indicate that the transition may be strongest for light polarized parallel to the $\mathrm{Cu}-\mathrm{O}$ planes as was also indicated in reflectance measurements, Ref. 12. The sharp feature may be due to a bound excitation that is related to interband excitations responsible for the broad absorption centered near 2.7 $\mathrm{eV}$, which is a common characteristic of the copper-oxide perovskite materials. This broad feature is similar to an optical structure derived from a calculated band structure for the material, although shifted somewhat in energy. ${ }^{38}$ The similarity between the calculated and measured optical spectra in this energy range suggests that interband transitions are a reasonable description for the broad feature. The existence of free carriers in these bands apparently frustrates the bound excitation so that it is only "turned on" when the material is nonmetallic. The nature of this mechanism is still not understood.

\section{IV. $\mathrm{La}_{2} \mathrm{Sr}_{x} \mathrm{CuO}_{4-\delta}$}

As mentioned above, the previously reported behavior of a 2.1-eV feature in $\mathrm{La}_{2-x} \mathrm{Sr}_{x} \mathrm{CuO}_{4-\delta}$ is similar to that of the $1.7-\mathrm{eV}$ features of the other superconducting compounds. $^{28}$ The $2.1-\mathrm{eV}$ feature may also be due to a bound charge-transfer excitation with a different energy due to the sixfold coordination of the $\mathrm{Cu}$ site. There is also the broad feature near $2.7 \mathrm{eV}$ that is common to these materials.

It is interesting to compare the spectrum of $\mathrm{Sr}_{2} \mathrm{CuO}_{3}$, which may be considered the end point of $\mathrm{Sr}$ substitution. ${ }^{32}$ As $\mathrm{Sr}$ is added in $\mathrm{La}_{2-x} \mathrm{Sr}_{x} \mathrm{CuO}_{4-\delta}$ beyond $x \sim 0.2$, oxygen vacancies increase. At complete substitution of $\mathrm{Sr}$, half of the oxygen atoms are missing from the 
$\mathrm{Cu}-\mathrm{O}$ planes so that the $\mathrm{Cu}$ atoms now have squareplanar coordination perpendicular to the plane as with $\mathrm{Cu}(1)$ in $\mathrm{YBa}_{2} \mathrm{Cu}_{3} \mathrm{O}_{7}$. The 1.5-3.0-eV spectrum for $\mathrm{Sr}_{2} \mathrm{CuO}_{3}$ is very similar to that of $\mathrm{La}_{2} \mathrm{CuO}_{4-\delta}$, as shown in Fig. 7. In fact, the $2.1-\mathrm{eV}$ feature seems even stronger, suggesting a strong role of out-of-plane oxygen. Note also the feature near $4.1 \mathrm{eV}$, which suggests additional oxygen vacancies in the plane resulting in some twofoldcoordinated $\mathrm{Cu}$ sites. The material $\mathrm{Bi}_{2} \mathrm{Sr}_{2} \mathrm{CuO}_{6}$ also has $\mathrm{Cu}-\mathrm{O}$ planes with the sixfold coordination, and has similar spectral dependence on conductivity with respect to the $2.1-\mathrm{eV}$ region, as shown in Figs. 7 (a) and $7(\mathrm{~b}) .{ }^{17}$

$$
\text { V. }(\mathrm{Bi}, \mathrm{Tl})_{2}(\mathrm{Sr}, \mathrm{Ba})_{2} \mathrm{Ca}_{n-1} \mathrm{Cu}_{n} \mathrm{O}_{4+2 n}
$$

Another family of superconductors, $(\mathrm{Bi}, \mathrm{Tl})_{2}(\mathrm{Sr}, \mathrm{Ba})_{2} \mathrm{Ca}_{n-1} \mathrm{Cu}_{n} \mathrm{O}_{4+2 n}$, includes either bismuth-oxygen or thallium-oxygen layers. ${ }^{39}$ The structure for $n=2$ is illustrated in Fig. 2(c). Phases have also been observed for $n=1$ and 3, which differ by removing or adding adjacent $\mathrm{Cu}-\mathrm{O}$ and $\mathrm{Ca}$ layers. The $n=1 \mathrm{ma}$ terial has one $\mathrm{Cu}-\mathrm{O}$ plane with sixfold coordination and was mentioned above; the $n=2$ material has two fivefold square-pyramidal coordination planes, and the $n=3 \mathrm{ma}$ terial has these two planes and an additional fourfold

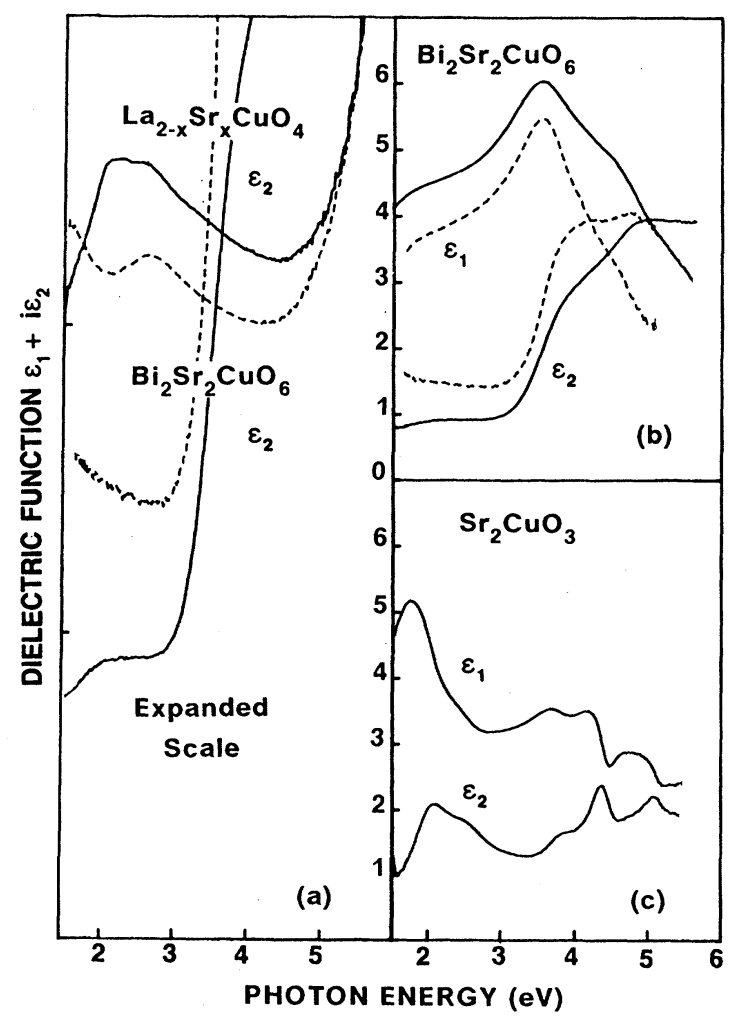

FIG. 7. Measured dielectric function for compounds with $\mathrm{Cu}$ sites having two apex oxygen neighbors: (a) expanded scale comparing nonmetallic (solid) and superconducting (dashed) compositions of $\mathrm{La}_{2-x} \mathrm{Sr}_{x} \mathrm{CuO}_{4}$ and $\mathrm{Bi}_{2} \mathrm{Sr}_{2} \mathrm{CuO}_{6}$, sixfold $\mathrm{O}$ coordination of $\mathrm{Cu}$ sites; (b) $\mathrm{Bi}_{2} \mathrm{Sr}_{2} \mathrm{CuO}_{6}$; (c) $\mathrm{Sr}_{2} \mathrm{CuO}_{3}$, fourfold coordination. coordinated plane.

Unlike the previous families, the $\mathrm{Bi}-\mathrm{Tl}$ superconductors have strong optical features that do not originate with the electronic structure of the $\mathrm{Cu}-\mathrm{O}$ plane. The $\mathrm{Bi}$ structure has been prepared with both $\mathrm{Fe}$ and Co replacing $\mathrm{Cu}^{40}$ The spectra of Fig. 8 show that the higherenergy structure is hardly affected even by complete substitution of $\mathrm{Cu}$ by $\mathrm{Co}$ or $\mathrm{Fe}$. In contrast, the spectrum obtained when $\mathrm{Bi}$ is replaced by $\mathrm{Tl}$, Fig. $8(\mathrm{~b})$, is significantly different. Therefore, we assign the absorption thresholds at 3.8 and $4.8 \mathrm{eV}$ to transitions in the Bi$\mathrm{O}$ plane. Corresponding transitions in the T1-O planes are at 3.5 and $5 \mathrm{eV}$. A comparison with spectra from plateletlike single crystals ${ }^{41}$ suggests an orientation dependence to these features, particularly the 3.7-3.9-eV threshold, with stronger absorption occurring for light polarized within the $a-b$ plane direction.

As with the other families, these materials also show a broad feature near $2.7 \mathrm{eV}$, apparently from the $\mathrm{Cu}-\mathrm{O}$ structure. Interestingly, however, the Co-substituted material also shows a feature in this energy range and may have a similar charge-transfer gap. As mentioned above, the $n=2$ material can be synthesized with $\mathrm{Y}$, which yields a nonsuperconducting material that shows the 1.7eV optical feature. The $n=1$ phase, which has sixfold coordination, has a $T_{c}$ of about $10 \mathrm{~K}$, and can be made nonconducting by reducing the oxygen composition. The spectrum for this composition shows a shoulder at $2.1 \mathrm{eV}$

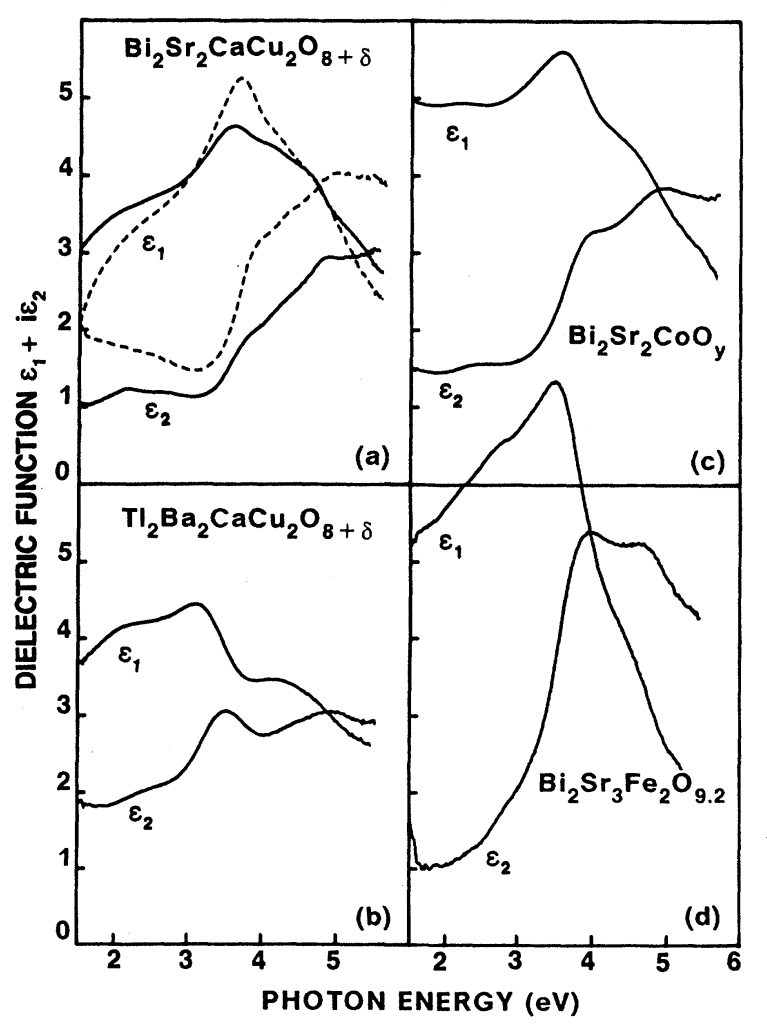

FIG. 8. Measured dielectric function for compounds in the Bi-Tl structural family. Dashed curve corresponds to a (001) single-crystal surface, Ref. 41. 
similar to that for undoped $\mathrm{La}_{2} \mathrm{CuO}_{4}$, Fig. 7(a). Therefore, we see that our measurements of this family are in good agreement with our structural assignments above.

$$
\text { VI. } \mathrm{Pb}_{2} \mathrm{Sr}_{2} \mathrm{ACu}_{3} \mathrm{O}_{8+\delta}
$$

Finally, we briefly consider the superconducting family $\mathrm{Pb}_{2} \mathrm{Sr}_{2} \mathrm{ACu}_{3} \mathrm{O}_{8+\delta} \quad(A=\mathrm{Ln}$, or $\mathrm{Ln}+\mathrm{Sr}$ or $\mathrm{Ca}) .^{42}$ This family has a structure similar to that of $\mathrm{YBa}_{2} \mathrm{Cu}_{3} \mathrm{O}_{7-x}$ with both $\mathrm{Cu}(2)$ - and $\mathrm{Cu}(1)$-like planes. However, the $\mathrm{Cu}(1)$ plane is sandwiched between $\mathrm{Pb}-\mathrm{O}$ planes. Depending on the composition, $A$, the material can be made nonconducting or metallic and superconducting. These materials were more difficult to polish, but representative spectra are shown in Fig. 9. As expected, the nonconducting sample has a weak $1.7-\mathrm{eV}$ feature. There is also a strong absorption structure at higher energy similar to that in the $\mathrm{Bi}$ material, which we tentatively assign to $\mathrm{O}$ $\mathrm{Pb}$ charge-transfer excitations.

Somewhat unexpectedly, we do not see the 4.1-eV feature, even though the linear O-Cu-O structures should be present. There are several possible explanations for this. The actual oxygen composition in these materials has been difficult to determine, ${ }^{43}$ so the $\mathrm{Cu}(1)$ sites may also have oxygen coordination in the plane. Bonding between the oxygen atoms and the $\mathrm{Pb}$ layer may have a stronger influence on the $\mathrm{O}-\mathrm{Cu}-\mathrm{O}$ complex than did the ionic $\mathrm{Ba}$ atoms in $\mathrm{YBa}_{2} \mathrm{Cu}_{3} \mathrm{O}_{7-x}$, causing behavior more like that of $\mathrm{CrCuO}_{2}$. The reported bond length between the oxygen and the $\mathrm{Cu}$ in this plane is $1.89 \AA$ rather than the $1.80 \AA$ of $\mathrm{YBa}_{2} \mathrm{Cu}_{3} \mathrm{O}_{6}$, and may have a strong effect on charge-transfer excitations. Finally, the strong absorption associated with the $\mathrm{Pb}$ may obscure a weak feature.

\section{CONCLUSIONS}

We have used optical spectroscopy to explore the separation and localization of the electronic structure originating at specific chemical substructures of these materials. Not surprisingly, the effects of this separation are most strongly apparent for nonconducting compositions. The optical spectra have characteristics that are common among different families, as well as some that are specific to particular materials. We have related the $4.1-\mathrm{eV}$ absorption to the linear $\mathrm{O}-\mathrm{Cu}^{+}-\mathrm{O}$ structure and revealed the importance of isolation in activating it. We have associated the $1.7-\mathrm{eV}$ feature with $\mathrm{Cu}-\mathrm{O}$ perovskite planes of either fourfold or fivefold coordination, and have shown that the existence of free carriers in these planes frustrates this bound excitation. The similarity of the

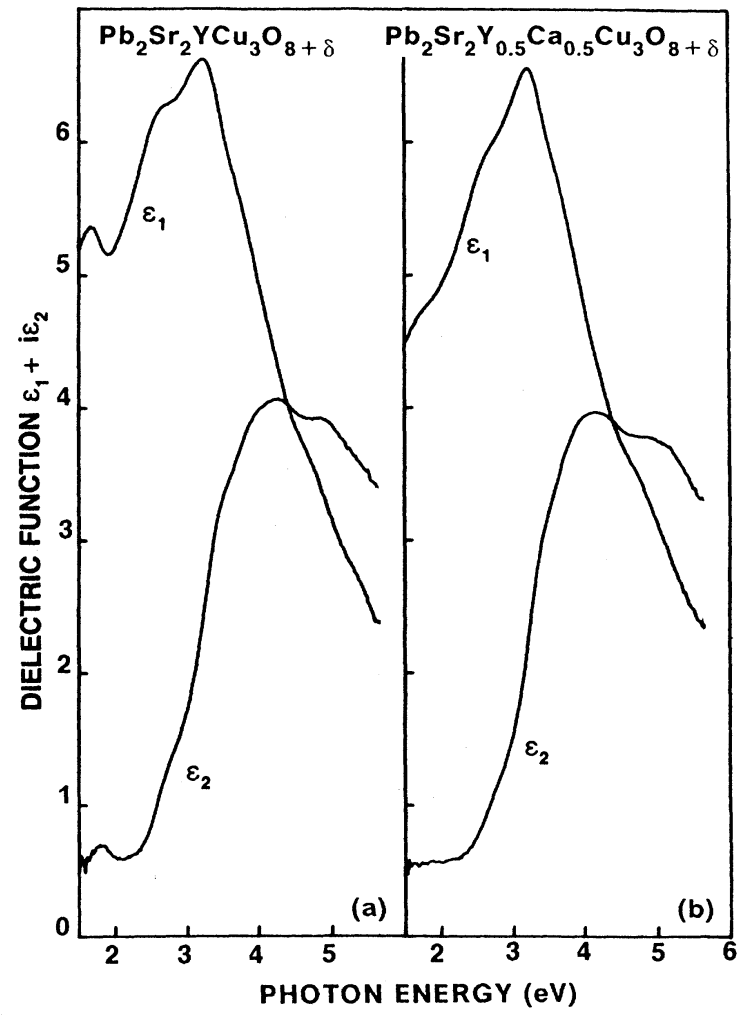

FIG. 9. Measured dielectric function for $\mathrm{Pb}_{2} \mathrm{Sr}_{2} \mathrm{ACu}_{3} \mathrm{O}_{8+\delta}$ : (a) nonmetallic; (b) metallic and superconducting, $T_{c}=65 \mathrm{~K}$.

1.7-eV optical behavior for the fourfold and fivefold coordinated planes is particularly interesting in light of the new $n$-type superconductor with fourfold coordination, and this, combined with the difference in the sixfold coordinated materials, suggests the possible importance of the apex oxygen atoms in determining the ability to introduce carriers into the plane. Our results also indicate similar electronic structure in related materials that have not yet shown superconductivity, encouraging further investigations of them.

\section{ACKNOWLEDGMENTS}

We are grateful to George Hull for ac susceptibility characterization, and to Paul Miceli, M. S. Hegde, and Ross McKinnon for helpful discussions.
${ }^{*}$ Current address: Chimie de la Matiere Condensée, Université Pierre et Marie Curie, 75005 Paris, France.

${ }^{1}$ J.-M. Tarascon, W. R. McKinnon, L. H. Greene, G. W. Hull, and E. M. Vogel, Phys. Rev. B 36, 226 (1987).

${ }^{2}$ P. K. Gallagher, J. M. O'Bryan, S. A. Sunshine, and D. W. Murphy, Mater. Res. Bull. 22, 995 (1987).

${ }^{3}$ J.-M. Tarascon, P. Barboux, P. F. Miceli, L. H. Greene, G. W. Hull, M. Eibschutz, and S. A. Sunshine, Phys. Rev. B 37,
7458 (1988).

${ }^{4}$ M. K. Kelly, P. Barboux, J.-M. Tarascon, D. E. Aspnes, W. A. Bonner, and P. A. Morris, Phys. Rev. B 38, 870 (1988).

${ }^{5}$ J.-M. Tarascon, P. Barboux, P. F. Miceli, B. G. Bagley, L. H. Greene, G. W. Hull, and M. Giroud, J. Phys. (Paris) Colloq. 49, C8-2081 (1988).

${ }^{6}$ D. E. Aspnes and A. A. Studna, Appl. Opt. 14, 220 (1975); Rev. Sci. Instrum. 43, 291 (1978). 
${ }^{7}$ I. Bozovic, K. Char, S. J. B. Yoo, A. Kapitulnik, M. R. Beasley, T. H. Geballe, Z. Z. Wang, S. Hagen, N. P. Ong, D. E. Aspnes, and M. K. Kelly, Phys. Rev. B 38, 5077 (1988).

${ }^{8}$ M. Garriga, J. Humlíček, M. Cardona, and E. Schönherr, Solid State Commun. 66, 1231 (1988).

${ }^{9}$ J. Humlíček, M. Garriga, and M. Cardona, Solid State Commun. 67, 589 (1988).

${ }^{10}$ H. P. Geserich, B. Koch, G. Scheiber, J. Geerk, H. C. Li, G. Linker, W. Weber, and W. Assmus, Physica 153-155C, 661 (1988).

${ }^{11}$ U. Venkateswaran, K. Syassen, H.-J. Mattausch, and E. Schönherr, Phys. Rev. B 38, 7105 (1988).

${ }^{12}$ M. P. Petrov, A. I. Grachev, M. V. Krasin'kova, A. A. Nechitailov, V. V. Profofiev, V. V. Poborchy, S. I. Shagin, and N. F. Kartenko, Solid State Commun. 67, 1197 (1988).

${ }^{13}$ J. Fink, N. Nücker, H. Romberg, and S. Nakai, Proceedings of the International Symposium on Electronic Structures of High-Temperature Superconductors, Roma, 1988 (unpublished).

${ }^{14}$ S. Sunshine, L. F. Schneemeyer, T. Siegrist, D. C. Douglas, J. Waszczak, R. J. Cava, F. M. Gyorgy, and D. W. Murphy, Chem. Mater. 1, 331 (1989), and references therein.

${ }^{15}$ Keiichi Edamatsu, Mikihiko Ikezawa, Hiroshi Tokailin, Takashi Takahashi, and Takasi Sagawa, J. Phys. Soc. Jpn. 55, 2880 (1986).

${ }^{16}$ T. Ishiguro, N. Ishizawa, N. Mizutani, and M. Kato, J. Solid State Chem. 49, 232 (1983); F. A. Benko and F. P. Koffyberg, Can. J. Phys. 63, 1306 (1985).

${ }^{17}$ J.-M. Tarascon, P. Barboux, G. W. Hull, R. Ramesh, L. H. Greene, M. Giroud, M. S. Hegde, and W. R. McKinnon, Phys. Rev. B 39, 4316 (1989).

${ }^{18}$ P. F. Miceli, J.-M. Tarascon, L. H. Greene, P. Barboux, F. J. Rotella, and J. D. Jorgensen, Phys. Rev. B 37, 5932 (1988).

${ }^{19}$ A. Bianconi, A. Congiu Castellano, M. De Santis, P. Rudolf, P. Lagarde, A. M. Flank, and A. Marcelli, Solid State Commun. 63, 1009 (1987).

${ }^{20}$ N. Nücker, J. Fink, J. C. Fuggle, P. J. Durham, and W. M. Temmerman, Phys. Rev. B 37, 5158 (1988).

${ }^{21}$ H. Oyanagi, H. Ihara, T. Matsubara, T. Matsushita, M. Hirabayashi, M. Tokumoto, K. Murata, N. Terada, K. Senzaki, T. Yao, H. Iwaski, and Y. Kimura, Jpn. J. Appl. Phys. 26, L1233 (1987).

${ }^{22}$ F. Baudelet, G. Collin, E. Dartyge, A. Fontaine, J. P. Kappler, G. Krill, J. P. Itie, J. Jegoudez, M. Maurer, Ph. Monod, A. Revcolevchi, H. Tolentino, G. Tourillon, and M. Verdaguer, Z. Phys. B 69, 141 (1987).

${ }^{23}$ S. M. Heald, J. M. Tranquada, A. R. Moodenbaugh, and Youwen Xu, Phys. Rev. B 38, 761 (1988).

${ }^{24}$ J. Kircher, M. Garriga, C. Thomsen, M. Cardona, P. Muru- garaj, and J. Maier (unpublished).

${ }^{25}$ Walter Dannhauser and Philip A. Vaughan, J. Am. Chem. Soc. 77, 896 (1955).

${ }^{26}$ M. K. Kelly, Siu-Wai Chan, K. Jenkin II, D. E. Aspnes, P. Barboux, and J.-M. Tarascon, Appl. Phys. Lett. 53, 2333 (1988).

${ }^{27}$ J. B. Torrance, Y. Tokura, A. Nazzal, and S. S. P. Parkin, Phys. Rev. Lett. 60, 542 (1988).

${ }^{28}$ S. Etemad, D. E. Aspnes, M. K. Kelly, R. Thompson, J.-M. Tarascon, and G. W. Hull, Phys. Rev. B 37, 3396 (1988).

${ }^{29}$ R. L. Greene, H. Maletta, T. S. Plaskett, J. G. Bednorz, and K. A. Muller, Solid State Commun. 63, 379 (1987).

${ }^{30}$ J. M. Tranquada, A. H. Moudden, A. I. Goldman, P. Zolliker, D. E. Cox, G. Shirane, S. K. Sinha, D. Vaknin, D. C. Johnston, M. S. Alverez, and A. J. Jacobson, Phys. Rev. B 38, 2477 (1988).

${ }^{31}$ T. Siegrist, S. M. Zahurak, D. W. Murphy, and R. S. Roth, Nature 334, 231 (1988).

${ }^{32}$ Hanskarl Müller-Buschbaum, Angew. Chem. Int. Ed. Engl. 16, 674 (1977).

${ }^{33}$ Y. Tokura, H. Takagi, and S. Uchida, Nature 337, 345 (1989).

34J.-M. Tarascon, E. Wang, L. H. Greene, B. G. Bagley, G. W. Hull, S. M. D'Egidio, P. F. Miceli, Z. Z. Wang, T. W. Jing, J. Clayhold, D. Brawner, and N. P. Ong (unpublished).

${ }^{35}$ C. Michel and B. Raveau, J. Solid State Chem. 43, 73 (1982).

36J. Zaanen, G. A. Sawatzky, and J. W. Allen, Phys. Rev. Lett. 55, 418 (1985).

${ }^{37}$ J. C. Fuggle, P. J. W. Weijs, R. Schoorl, G. A. Sawatzky, J. Fink, N. Nücker, P. J. Durham, and W. M. Temmerman, Phys. Rev. B 37, 123 (1988).

${ }^{38}$ Guang-Lin Zhao, Yongnian $\mathrm{Xu}, \mathrm{W}$. Y. Ching, and $\mathrm{K}$. W. Wong, Phys. Rev. B 36, 7203 (1987).

${ }^{39}$ R. V. Kasowski, W. Y. Hsu, and F. Herman, Phys. Rev. B 38, 6470 (1988)

40J.-M. Tarascon, P. F. Miceli, P. Barboux, D. M. Hwang, G. W. Hull, M. Giroud, L. H. Greene, Yvon Le Page, W. R. McKinnon, E. Tselepis, G. Pleizier, M. Eibschutz, D. A. Neumann, and J. J. Rhyne, Phys. Rev. B 39, 11587 (1989).

${ }^{41}$ P. A. Morris, W. A. Bonner, B. G. Bagley, G. W. Hull, N. G. Stoffel, L. H. Greene, and M. Giroud, Appl. Phys. Lett. 53, 249 (1988).

${ }^{42}$ R. J. Cava, B. Batlogg, J. J. Krajewski, L. W. Rupp, L. F. Schneemeyer, T. Siegrist, R.-B. vanDover, P. Marsh, W. F. Peck, Jr., P. K. Gallagher, S. H. Glarum, J. H. Marshall, R. C. Farrow, J. V. Waszczak, R. Hull, and P. Trevor, Nature 336, 211 (1988).

${ }^{43}$ P. K. Gallagher, H. M. O'Bryan, R. J. Cava, A. C. W. P. James, D. W. Murphy, J. J. Krajewski, W. F. Peck, Jr., and J. V. Waszczak (unpublished). 